\title{
Recovery of recombinant Mycobacterium tuberculosis antigens fused with cell wall- anchoring motif (LysM) from inclusion bodies using non-denaturing reagent $(\mathrm{N}$ - laurylsarcosine)
}

Anhar Danial Mustafa', Jeevanathan Kalyanasundram', Sarah Sabidi ${ }^{1}$, Adelene Ai-Lian Song ${ }^{2,4}$, Maha Abdullah ${ }^{3}$, Raha Abdul Rahim ${ }^{1,4}$ and Khatijah Yusoff ${ }^{2,45^{*}}$ (i)

\begin{abstract}
Background: The current limitations of conventional BCG vaccines highlights the importance in developing novel and effective vaccines against tuberculosis (TB). The utilization of probiotics such as Lactobacillus plantarum for the delivery of TB antigens through in-trans surface display provides an effective and safe vaccine approach against TB. Such non-recombinant probiotic surface display strategy involves the fusion of candidate proteins with cell wall binding domain such as LysM, which enables the fusion protein to anchor the L. plantarum cell wall externally, without the need for vector genetic modification. This approach requires sufficient production of these recombinant fusion proteins in cell factory such as Escherichia coli which has been shown to be effective in heterologous protein production for decades. However, overexpression in E. coli expression system resulted in limited amount of soluble heterologous TB-LysM fusion protein, since most of it are accumulated as insoluble aggregates in inclusion bodies (IBS). Conventional methods of denaturation and renaturation for solubilizing IBs are costly, time-consuming and tedious. Thus, in this study, an alternative method for TB antigen-LysM protein solubilization from IBs based on the use of non-denaturating reagent N-lauroylsarcosine (NLS) was investigated.

Results: Expression of TB antigen-LysM fusion genes was conducted in Escherichia coli, but this resulted in IBs deposition in contrast to the expression of TB antigens only. This suggested that LysM fusion significantly altered solubility of the TB antigens produced in E. coli. The non-denaturing NLS technique was used and optimized to successfully solubilize and purify $\sim 55 \%$ of the recombinant cell wall-anchoring TB antigen from the IBs. Functionality of the recovered protein was analyzed via immunofluorescence microscopy and whole cell ELISA which showed successful and stable cell wall binding to L. plantarum (up to 5 days).
\end{abstract}

Conclusion: The presented NLS purification strategy enables an efficient and rapid method for obtaining higher yields of soluble cell wall-anchoring Mycobacterium tuberculosis antigens-LysM fusion proteins from IBs in E. coli.

Keywords: Mycobacterium tuberculosis antigen, Lysine motif, Overexpression, Inclusion body, TB subunit vaccine, Nlauroylsarcosine

\footnotetext{
* Correspondence: kyusoff@upm.edu.my

2Department of Microbiology, Faculty of Biotechnology and Biomolecular

Sciences, Universiti Putra Malaysia, 43400 Serdang, Selangor, Malaysia

${ }^{4}$ Institute of Bioscience, Universiti Putra Malaysia, 43400 Serdang, Selangor,

Malaysia

Full list of author information is available at the end of the article
}

(c) The Author(s). 2019 Open Access This article is distributed under the terms of the Creative Commons Attribution 4.0 International License (http://creativecommons.org/licenses/by/4.0/), which permits unrestricted use, distribution, and reproduction in any medium, provided you give appropriate credit to the original author(s) and the source, provide a link to the Creative Commons license, and indicate if changes were made. The Creative Commons Public Domain Dedication waiver (http://creativecommons.org/publicdomain/zero/1.0/) applies to the data made available in this article, unless otherwise stated. 


\section{Background}

Tuberculosis (TB) is one of the leading causes of morbidity and mortality in humans, and it represents a major public health problem in many developing and underdeveloped countries [1]. Almost one third of the world population is latently infected with TB with around 1.6 million deaths recorded in 2017 [2]. Thus, the prevention of $\mathrm{TB}$ is crucial particularly when the current standard vaccine, Bacille Calmette-Guérin (BCG) vaccine, has shown to be suboptimal and less effective $(0-80 \%)$ in tropical and sub-tropical regions [3]. This underlines the urgency in developing second generation vaccines which could function as a competent prophylactic vaccine and/or a booster vaccine that improves immunity in BCG-vaccinated individuals.

A mucosal antigen delivery strategy using probiotic lactic acid bacteria such as Lactobacillus plantarum as a carrier has the potential to be developed as an effective TB vaccine. It was reported that the presence of $L$. plantarum with $M$. tuberculosis antigens can act as an adjuvant and help improve the immune response to a favorable Th1 response, prerequisite for effective humoral and cell-mediated immunity [4]. Other advantages of using $L$. plantarum as a mucosal vaccine delivery vehicle has been described previously [5-7]. These antigen carriers are able to persist and colonize certain regions in the mucosa. The surface display of antigenic protein can be expressed by the bacteria intracellularly and secreted for outer cell wall attachment [8,9]. Alternatively, antigenic protein can also be surface displayed in-trans, by first producing the protein fused with binding domain in a separate expression system such as in Escherichia coli. The target fusion protein will then be purified and subsequently introduced externally to $L$. plantarum for cell surface anchoring $[7,10,11]$. The latter method produces a non-genetically modified organism (GMO) bacterial vaccine, which provides a safer vaccine option particularly with impending post-antibiotic era. However, an appropriate anchor protein is required for both secretion and in-trans surface display approach. For instance, the LPXTG anchor motif that binds covalently to peptidoglycan can only be used in the first binding approach [12], while the lysine motif protein domain (LysM) is more suitable for the second binding approach as it binds non-covalently to the peptidoglycan layer $[7,13]$.

In recent years, extensive progress on TB subunit vaccine research has produced several promising vaccines which are currently being tested at different stages of clinical trials [14]. These subunit vaccines consist of effective immunodominant TB proteins, including Ag85B, Rv2031 and Rv0475. The Ag85B is a mycolyltransferase that is able to induce both humoral and cell-mediated immune responses in $M$. tuberculosis-infected subjects
[15]. The Rv2031 or HspX, on the other hand, is a stress protein, induced by anoxia which has a proposed role in maintaining long-term viability during latent and asymptomatic infections [16, 17]. The Rv0475 or HbhA is a protein required for extrapulmonary dissemination [16]. These proteins are considered immunodominant proteins as they have been demonstrated to induce strong immune responses in different animal models [18] as well as $\mathrm{T}$ cell induction in human infected with $M$. tuberculosis [17]. The combination of these immunodominant antigens within multiple epitope fusion proteins, similar to the current TB subunit trial vaccines, have been shown to extensively improve the immunogenicity and protective efficacy of subunit vaccine. This is due to the higher potential of immune-reactivity of multiple immunogenic proteins compared to a single immunogenic protein [18].

E. coli is the most common host cell for efficient and safe expression of native or recombinant antigens from M. tuberculosis [18]. Although protein production can be readily optimized in E.coli, overexpression generally leads to a significant amount of the protein being misfolded or/and aggregated [19]. Hitherto, most recombinant $\mathrm{TB}$ vaccine candidates have been purified at a significant lower amounts since most of them were detected to be accumulated in inclusion bodies (IBs) [15, 18]. These protein are usually recovered from the IBs by initial denaturation with urea or guanidine hydrochloride followed by protein renaturation steps [20]. This method is expensive, tedious and often resulted in low recovery yields of 15-25\% [19]. Another alternative approach is to use a mild detergent, such as N-lauroylsarcosine (NLS), which has been shown previously, to effectively recover soluble properly folded proteins from IBs formed in $E$. coli under non-denaturing condition [20-22].

In this study, the cell wall-anchoring recombinant protein ARL was constructed and expressed in E. coli. The ARL protein consists of $M$. tuberculosis Ag85B $\mathrm{B}_{101-}$ 115,126-140,261-275, Rv047534-59 and Rv2031 $41-70$, 95-108 epitopes (AR) fused with the LysM anchoring domain of AcmA, a N-acetylglucosaminidase of Lactococcus lactis MG1363 [23]. However, it was observed that the fusion protein ARL was accumulated in IBs. Thus, the aim of this study, was to recover a soluble form of the ARL protein from the IBs using the NLS treatment. Once the target protein was recovered, the binding capability of ARL was tested via in vitro binding studies onto L. plantarum Pa21 cell surface. The retaining of the ARL-LysM cell wall binding ability, helps to determine the suitability of such pre-treatment assay for recovering soluble TB fusion protein from the IBs in the future. The NLS pre-solubilization step for IBs of other M. tuberculosis antigenic proteins fused with cell wall-anchoring motif 
such as LysM may be advantageous since this approach is rapid, cheaper and more effective than the conventional denaturing/renaturing method.

\section{Results}

\section{Development and overexpression of pRSF:ARL}

The construction of pRSF:ARL and pRSF:AR (Fig. 1) was successfully achieved as verified via BamHI/NotI restriction enzyme analysis (Additional file 1: Figure S1) and sequence analyses (Additional file 2: Figure S2). Overexpression of ARL and AR, respectively, was obtained using pRSFDuet-1 vector in $E$. coli Rosetta (DE3) pLySs strain using IPTG as inducer (Fig. 2). Without induction, ARL was not observed in either insoluble (precipitant) or soluble (supernatant) fractions as indicated in Fig. 2 of lanes 2 and 3, respectively. Following induction with IPTG, an intense band was observed in the precipitant fraction (Fig. 2, lane 5) indicating that the overexpressed ARL was mostly deposited into IBs as opposed to the soluble or supernatant fraction (Fig. 2, lane 6). Interestingly, the total protein fraction (Fig. 2, lane 4) did not show visible ARL target protein band. This may be due to the concentration of ARL which was too low and therefore masked by host endogenous proteins compared to the precipitant fraction, a concentrated fraction containing mostly the ARL IBs. This was supported by the Western blot results where a clear band corresponding to ARL protein was observed in the total fraction sample. (Additional file 3: Figure S3). Densitometry analysis revealed that the overexpressed ARL protein in the insoluble fraction with the expected molecular weight of $\sim 45 \mathrm{kDa}$ (Fig. 2, lane 5), was $\sim 47 \%$ pure. Unlike the ARL protein, the AR protein of $24 \mathrm{kDa}$ was more prominently present in the soluble cell fraction (Fig. 2, lane 9) than in the insoluble cell fraction (Fig. 2, lane 8), suggesting that the fusion with LysM protein had affected the solubility of the expressed ARL.

\section{Extraction of ARL from IBs using NLS}

Effective NLS concentration is important to solubilize and extract maximum amount of target proteins from IBs. Thus, to achieve the optimal NLS concentration, treatment was carried out using ARL protein with varying NLS concentration of $0.5,1,3$, and $5 \%(\mathrm{w} / \mathrm{v})$ for $24 \mathrm{~h}$ at $20^{\circ} \mathrm{C}$ as depicted in Fig. 3a. The ARL IBs solubility improved with the increase of NLS concentration up to $5 \%(\mathrm{w} / \mathrm{v})$ NLS (Fig. 3c). The results also implied that a NLS concentration above $5 \%$ would have little impact in improving the solubilization of ARL IBs. This is because the ratio of soluble/insoluble protein solubilization of ARL IBs seems to reach a plateau value when higher NLS concentration was used (Fig. 3c) as shown by the ratio between NLS 3\% (0.498) and 5\% (0.609). This also indicated that there was still a fraction of partially or totally misfolded proteins present inside the IBs, which were unaffected by the NLS solubilization treatment.

a

\begin{tabular}{|c|c|c|c|c|c|}
\hline Plasmid & & & & & $\frac{\text { Expressed }}{\text { D }}$ \\
\hline pRSF:ARL & $6 \mathrm{xHis}$ & AR & Linker & lys $\mathbf{M}$ & ARL \\
\hline pRSF:AR & $6 \mathrm{xHis}$ & AR & & & AR \\
\hline
\end{tabular}

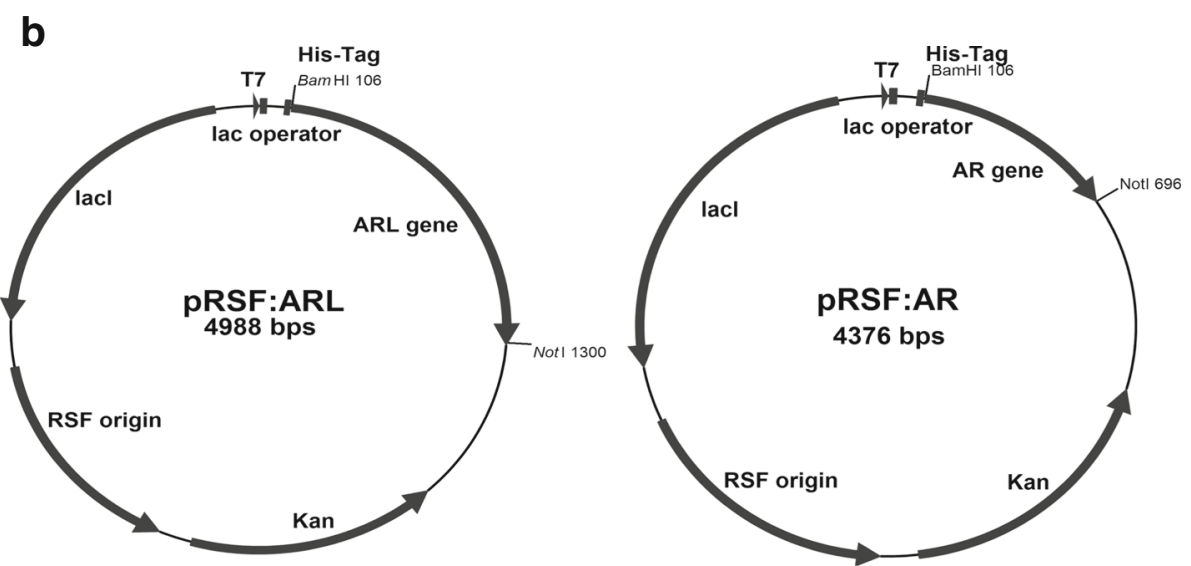

Fig. 1 a Schematic illustration of the fusion proteins encoded by PRSF:ARL expressing the LysM binding motif from L. lactis AcmA, and pRSF:AR missing the lysM sequence. $\mathbf{b}$ Map of the recombinant plasmids pRSF:ARL and pRSF:AR. Both ARL and AR genes were inserted between BamHI and Notl sites of pRSF:Duet-1 to construct pRSF:ARL and pRSF:AR expression plasmid, respectively 


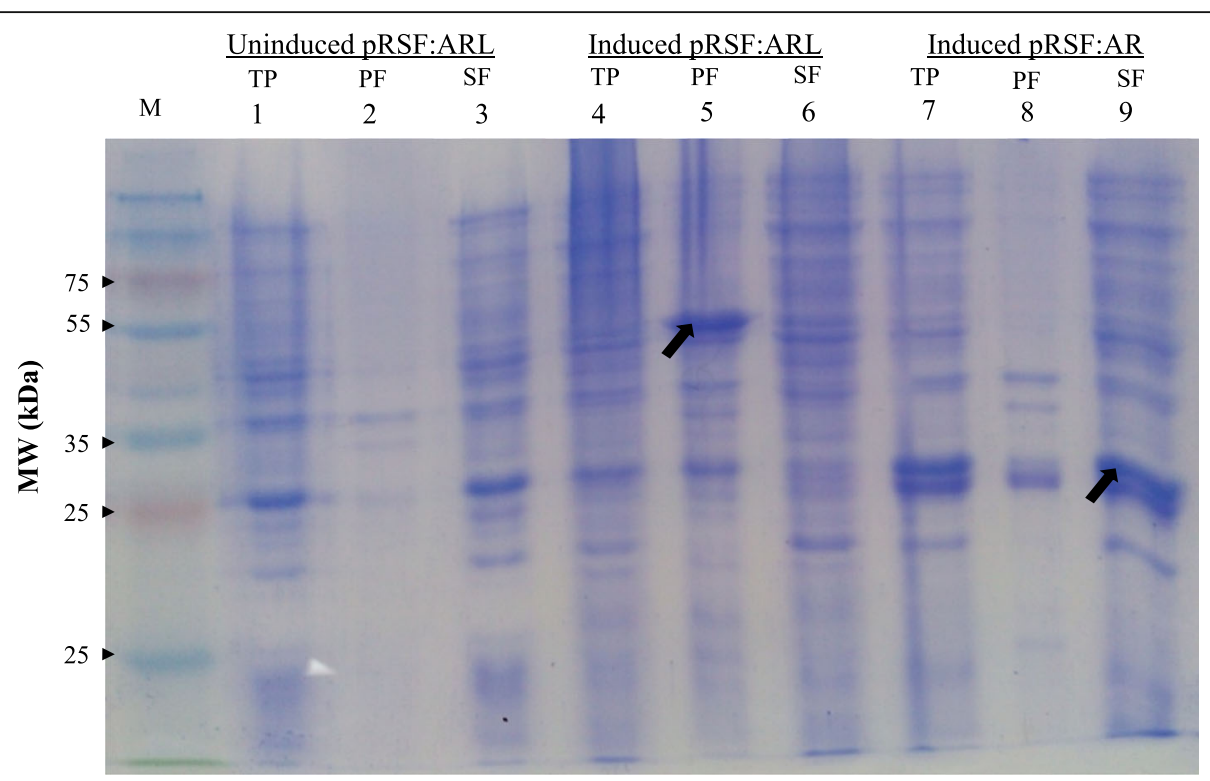

Fig. 2 Expression analysis of the ARL protein in E. coli. Positive transformant cells harbouring PRSF:ARL were induced, lysed and analyzed for protein expression by sodium dodecyl sulfate polyacrylamide (SDS-PAGE). A control batch of bacterial cells harbouring pRSF:AR was also induced and analyzed to compare AR $(\sim 24 \mathrm{kDa})$ solubility to that of ARL ( $45 \mathrm{kDa})$. Lanes 1-3, 4-6 and 7-9 correspond to the protein profile of uninduced cells harbouring PRSF:ARL, induced cells harbouring pRSF:ARL, and induced cells harbouring pRSF:AR, respectively. Lanes labeled with M, TP (lanes 1, 4 and 7), PF (lanes 2, 5 and 8) and SF (lanes 3, 6 and 9) refer to protein ladder marker (Fermentas, Canada), total protein,

precipitant fraction and supernatant fraction, respectively

Based on the densitometry analysis, the extractability of ARL IBs into the soluble form was most favorable with $5 \%(\mathrm{w} / \mathrm{v})$ NLS. At this concentration, ARL IBs were effectively solubilized (Table 1). NLS-solubilized ARL was then diluted to a final concentration of $0.1 \%$ NLS before being applied onto the $\mathrm{Ni}^{2+}$-NTA matrix column as to avoid inhibition of binding to the $\mathrm{Ni}^{2+}$-NTA- matrix by NLS [20]. Approximately 55.4\% of IBs containing ARL protein was able to be solubilized and bound to $\mathrm{Ni}^{2}$ ${ }^{+}$-NTA matrix before being eluted with elution buffer containing $500 \mathrm{mM}$ imidazole in two fractions (Elution 1 and Elution 2) which was combined afterwards (Fig. 3d). This one-step purification resulted in highly pure ARL protein with more than $98 \%$ purity. During the solubilization and purification process, the extractability of ARL IBs yielded a purified protein of $0.63 \mathrm{mg}$ per 0.1 g cell mass. Based on the SDS-PAGE analysis, the molecular weight of the purified ARL was estimated to be approximately $45 \mathrm{kDa}$ (Fig. 3d), similar to that of the expected ARL protein size. Protein recovery at every step of $5 \%(\mathrm{w} / \mathrm{v})$ NLS solubilization and purification is shown in Table 1.

\section{Binding capability of ARL onto $L$. plantarum cell wall}

In order to determine the binding capability of the solubilized ARL proteins, attachment of the purified ARL proteins onto L. plantarum cell wall was performed and subjected to immunofluorescence staining for qualitative evaluation and confirmation. As shown in Fig. 4a, ARL protein was successfully bound to the cell wall of $L$. plantarum. Bright fluorescence highlighting on the rod-shaped Lactobacilli cells was observed using phase contrast imaging indicating a successful attachment of ARL on the cell wall surface of the bacteria. Meanwhile, the negative control comprising bacterial cells suspended in PBS (Fig. 4b) showed no fluorescence signal.

To semi-quantitatively investigate and determine whether the ARL purified proteins were able to be stably anchored and displayed onto the $L$. plantarum cell surface, whole cell ELISA was performed over 5 days period (Fig. 5). The values of the absorbance $\left(\mathrm{OD}_{490} \mathrm{~nm}\right)$ correlated to the frequency by which ARL had attached onto the cell walls of $L$. plantarum, thus projecting the ARL binding stability each day from Day 0 to 4 . The ARL attached to L. plantarum showed a consistent pattern of binding stability that involved a slight reduction in absorbance reading at Day 2 followed by a gradual decrease of absorbance until Day 4 (Fig. 5).

\section{Discussion}

Inclusion bodies (IBs) in E. coli are dense and porous particles containing almost exclusively overexpressed and aggregated proteins [19]. The prevalence of protein aggregation in E. coli can be due to overexpression and/ or misfolded heterologous proteins. The overexpression of heterologous of protein has been posited to disrupt intracellular proteostasis which triggers formation of IBs a part of $E$. coli stress response, in order to retain 


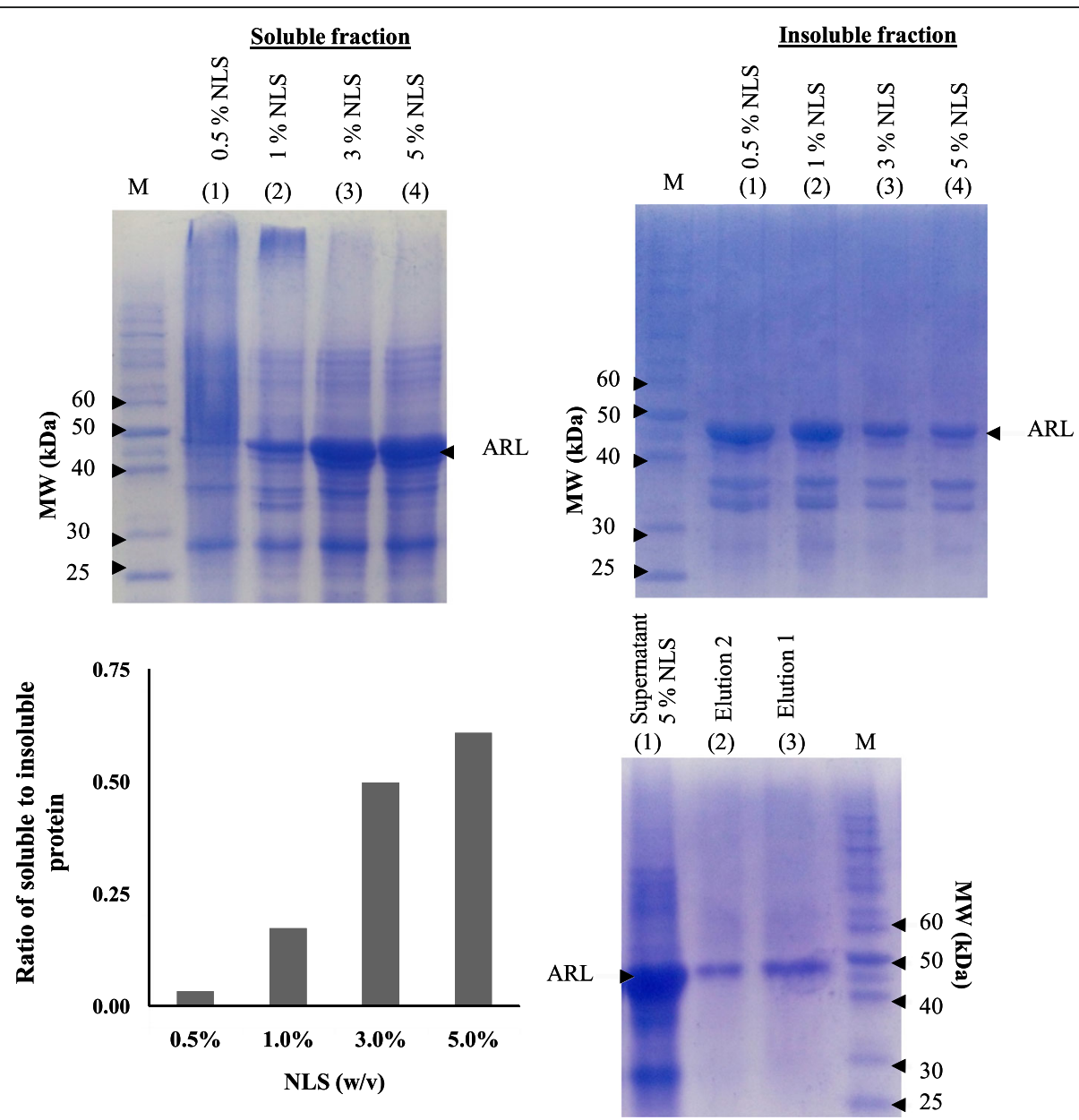

Fig. 3 Solubilization and purification of ARL inclusion bodies (IBs) using varying concentrations of 0.5 1, 3 and $5 \%$ (W/v) NLS a Soluble fractions of ARL after NLS treatment. $\mathbf{b}$ Insoluble fractions of ARL after NLS treatment. $\mathbf{c}$ Ratio of soluble protein to insoluble protein of ARL obtained from IBS solubilized with varying NLS concentration. d $5 \%$ NLS-treated ARL which was diluted to $0.1 \%$ NLS initially before the purification via the Ni ${ }^{2+}$-NTA affinity chromatography

protein equilibrium [24]. On the other hand, the irregularities in protein folding, especially misfolded proteins, tend to reveal higher hydrophobic regions which lead to rapid protein interaction thus promoting aggregation [25]. The common strategy of IBs solubilization uses denaturants such as urea and guanidine-hydrochloride with additional renaturation steps. This conventional method requires the linearization of the IBs protein via the removal of the disulfide linkages before allowing gradual refolding of the protein under optimized renaturing agent concentration with stabilizer and additive reagents [19]. However, hydrophobic interactions and incorrect disulfide bond formations severely damages protein renaturation [20]. Alternatively, the use of NLS, an ionic and non-denaturant detergent, has been shown previously to effectively solubilized IBs composed of various protein types [20-22]. Nonetheless, solubilization of IBs using NLS appears to be only

Table 1 ARL protein recoveries (per $0.1 \mathrm{~g}$ wet cell mass) from inclusion bodies (IBs) by 5\% (w/v) N-lauroylsarcosine (NLS) and its purification by $\mathrm{Ni}^{2+}$-NTA affinity chromatography

\begin{tabular}{llll}
\hline Stages of solubilization/purification & Total protein $(\mathrm{mg}) / 0.1 \mathrm{~g}$ cell wet mass & Target protein $(\mathrm{mg}) / 0.1 \mathrm{~g}$ cell wet mass & Purity $(\%)$ \\
\hline Cell lysate & 3.21 & 1.53 & 47 \\
Insoluble fraction/IBs & 1.9 & 1.14 & 60 \\
Soluble fraction after 5\% NLS treatment & 1.12 & 0.69 & 61.8 \\
Purified ARL after Ni ${ }^{2+}$-NTA affinity chromatography & 0.64 & 0.63 & 98 \\
Extractability (\%) from IBs & $33.68 \%$ & $55.42 \%$ & - \\
\hline
\end{tabular}




\section{a}

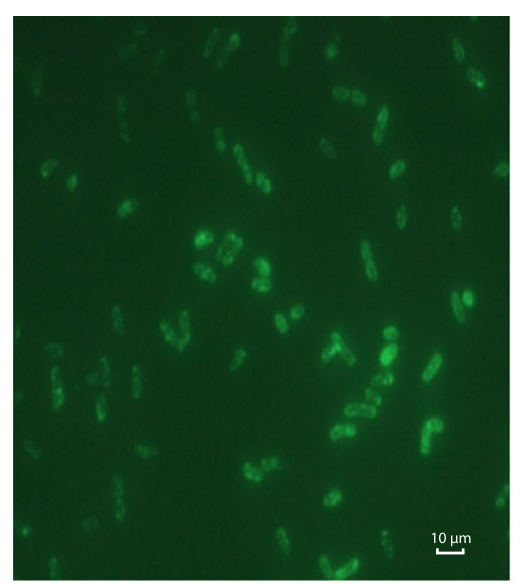

b

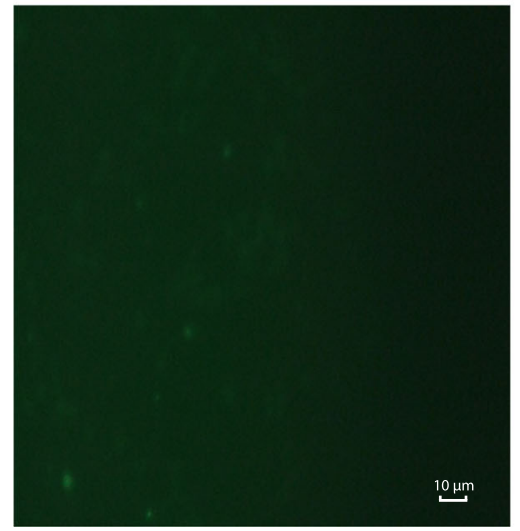

\section{Phase contrast}
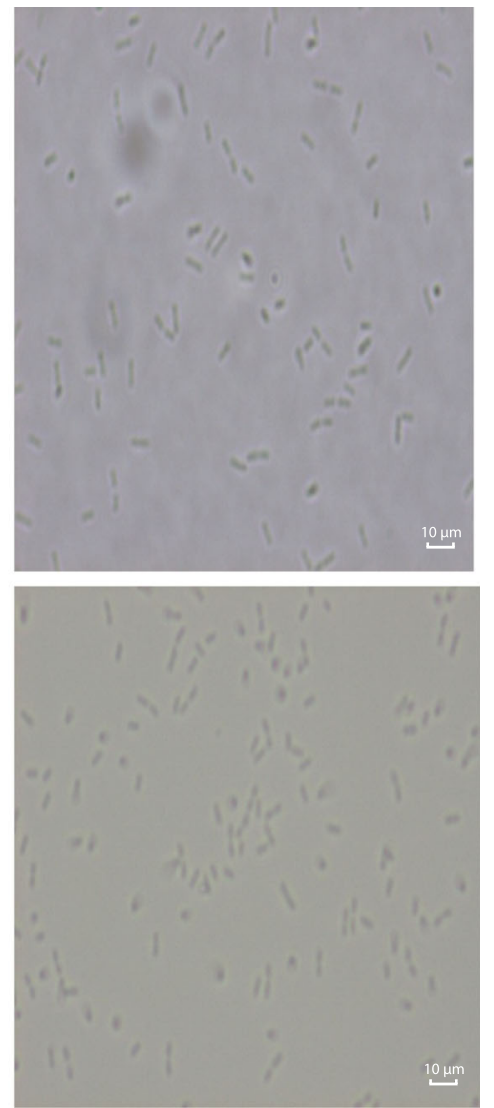

Fig. 4 Binding of ARL onto L. plantarum Pa21 cells. Fluorescence and phase contrast microscopy of L. plantarum cells incubated with a ARL protein and $\mathbf{b}$ PBS. The positive FITC signalling (designated by the green fluorescence) on L. plantarum cells incubated with ARL protein indicates successful ARL attachment to L. plantarum cell wall. The cells were observed under 100x objective in all frames

efficient against IBs harbouring partially folded protein aggregates [21]. Based on the proposed mechanism for IBs solubilization by NLS, the latter compound acts by penetrating the IBs pores and inhibiting aggregation of proteins via encapsulation of the proteins [22] and masking of their hydrophobic patches [20], thus canceling the interaction between partially folded proteins. On the other hand, IBs composed of primarily misfolded proteins are inherently insoluble and can only be solubilized with the conventional method.

The overexpression of ARL protein was achieved using the expression vector pRSFDuet-1 in $E$. coli which is based on an IPTG-inducible expression system. However, most of the expressed ARL protein were detected to be accumulated in IBs. This is in contrast to the AR protein, which was produced as a soluble protein under same expression system (see Fig. 2), suggesting that the fusion of LysM with AR protein may have affected ARL solubility. This formation of IBs can be a significant obstacle for the development of surface displayed, cell wall-anchored subunit TB vaccines especially in obtaining optimal quantity of proteins with correct conformational structure. Previous studies utilizing a similar approach of expressing various types of antigen-LysM fusions in $E$. coli expression host [7, 26-28] have yet to encounter this issue. There are various possible reasons for the fusion of LysM to AR which causes the resulting fusion protein to be deposited into IBs. It is possible that an increase in protein size as a result of the AR-LysM fusion may affect the efficiency of proper refolding in $E$. coli [29]. Moreover, the combination between AR and LysM as fusion protein may not be compatible and may cause protein-protein interaction effect that leads to improper and partial protein folding conformation which promotes protein aggregation and IBs formation [29].

The ARL IBs were solubilized using various NLS concentrations ranging from $0.5-5 \%(\mathrm{w} / \mathrm{v})$. Although a higher NLS concentration of $10 \%$ was reported to be able to solubilize $>95 \%$ of IBs, subsequent dilution to < $0.3 \%$ final concentration for $\mathrm{Ni}^{2+}-\mathrm{NTA}$ column purification and downstream processes destabilized the protein and promotes aggregation [22]. Therefore, a lower range 


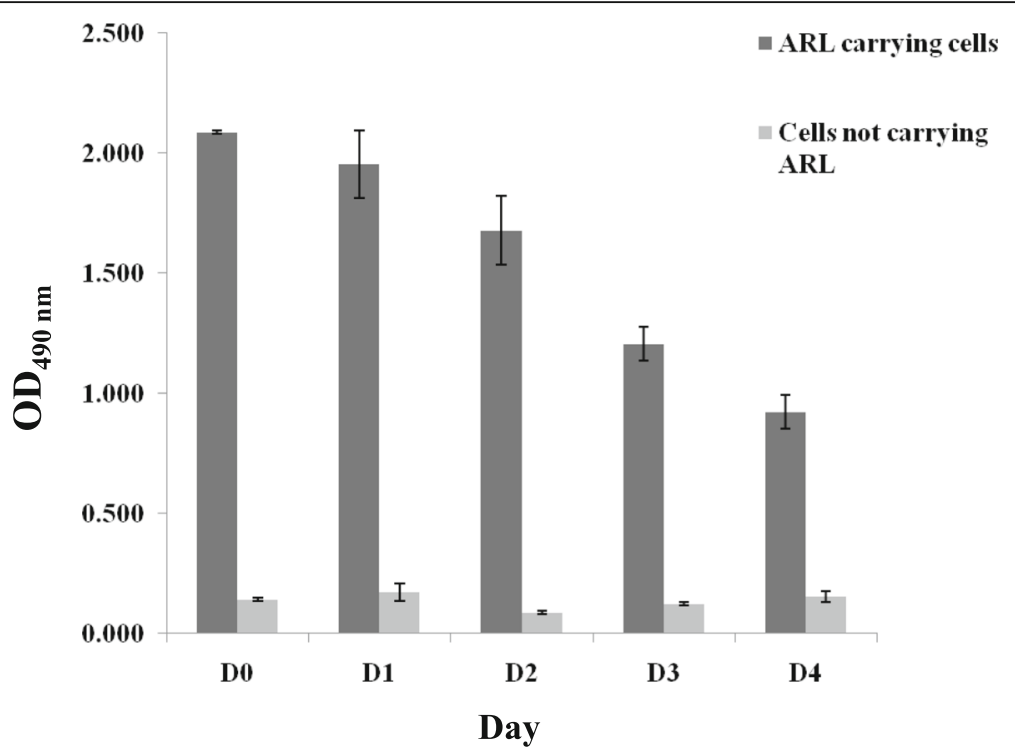

Fig. 5 Stability analysis of the ARL protein anchored onto cell surface of L. plantarum. The cells were incubated with ARL protein and were subjected to ELISA using mouse anti-His monoclonal IgGs (Novagen, USA) as primary antibody and goat anti-mouse IgG-HRP (Calbiochem, USA) as secondary antibody for the duration of 5 days (Day 0 to Day 4). Negative control was L. plantarum incubated with PBS

of NLS concentration up to $5 \%$ was tested instead. Among the NLS concentrations tested, 5\% NLS (w/v) was determined to be the most favorable NLS concentration for ARL IBs solubilization. In order to capture all of the solubilized protein on the affinity column, the NLS concentration needs to be less than $0.3 \%$ [21] since higher NLS concentration prevents effective binding of protein onto the column due to the masking of the His tag by the detergent [20]. However, the extreme dilution of the NLS from $5 \%(\mathrm{w} / \mathrm{v})$ to $0.3 \%(\mathrm{w} / \mathrm{v})$ post IBs solubilization in order to promote $\mathrm{Ni}^{2+}-\mathrm{NTA}$ column protein capturing, also has its limitation. The swift reduction of NLS concentration may impair its ability to prevent protein re-aggregation and precipitation. This limitation poses a major hurdle in upscaling fusion protein production in order to obtain suitable amount of protein for downstream process. [22]. Hence, the pretreatment NLS concentration in this study was diluted to $0.1 \%(\mathrm{w} / \mathrm{v})$ to improve capture of NLS-treated ARL to $\mathrm{Ni}^{2+}$-NTA column without the need for diluting the solubilized protein sample. Based on this single-step purification method, the protein recovery yield was approximately $55 \%$ at more than $98 \%$ purity. A final yield of $0.63 \mathrm{mg}$ of purified protein could be obtained per $0.1 \mathrm{~g}$ wet cell mass.

The functionality and stability of ARL to anchor to the cell wall of $L$. plantarum was then analysed via immunofluorescence microscopy and whole cell ELISA for qualitative and semi-quantitative analysis, respectively. Both methods showed that the binding of ARL to the L. plantarum cell wall was successfully achieved. Attachment of
ARL to the cell wall of $L$. plantarum was due to the triple LysM domain that binds non-covalently to peptidoglycan on the cell wall surface of L. plantarum [13]. Interestingly, the LysM motif can recognize and attach to a broad range of bacterial cell walls particularly of Gram-positive bacteria, such as Clostridium, Listeria, and Bacillus [11]. This feature is advantageous in making the ARL protein flexible for further optimization using a variety of bacteria as vaccine delivery vehicles. The ARL binding stability showed similar pattern as in other studies $[7,26]$ where consistent binding within a period of several days was observed. However, as shown in Fig. 5, gradual decrease of the absorbance values from the initial binding at Day 0 over the period of 5 days indicated that the binding stability of ARL may be reduced after a longer period of time. This reduction of ARL binding may be a consequence of proteolysis by Lactobacilli housekeeping proteases such as HtrA [30], which cleaves surface adhesion protein including that of the attached ARL protein on the Lactobacilli cell wall. Moreover, the occurrence of cell division may also result in the detachment of bound ARL to L. plantarum cell wall, thereby disrupting ARL binding stability. Ultimately, the successful cell wall binding of ARL acts as preliminary indicator that the solubilization of ARL IBs using NLS has resulted in functional protein conformation. Although this approach only focuses on the binding capability of ARL, it is postulated that the correlation between correctly folded protein and the functional LysM domain after NLS solubilization indicates strongly that the antigenic part (AR) of the protein may have 
retained its native and proper protein conformation which is important in triggering prophylactic immune response against TB. Hence, the immunogenicity of ARL attached to L. plantarum needs still to be investigated in future particularly via the in vivo studies.

\section{Conclusions}

In summary, an efficient and rapid method for obtaining soluble cell wall-anchoring M. tuberculosis ARL from IBs using NLS, is described. This purification strategy can potentially be used for the purification of other cell wall-anchoring fusion proteins that are expressed as IBs. It is recommended that this strategy is applied first as the reported method is a rapid and cost-effective option than that of the conventional method of IBs extraction via denaturation and renaturation procedures. If the NLS treatment still does not provide any significant recovery of soluble protein, the IBs are most likely composed of totally misfolded proteins, and thus requires the conventional method instead.

\section{Methods}

\section{Microorganisms and plasmids}

Lactococcus lactis MG1363 [23] was inoculated at $30{ }^{\circ} \mathrm{C}$ in M17 medium (Sigma, USA) before its genomic DNA was extracted and used for the amplification of the lys $\mathrm{M}$ binding motif of the $a c m A$ gene (accession no. U17696.1). Lactobacillus plantarum Pa21 cells [31] were used as the carrier vehicle to display $M$. tuberculosis antigens. Escherichia coli Rosetta (DE3) pLysS (Novagen, USA) was used as the expression host cell in combination with pRSF:DuetT-1 (Invitrogen, USA) as the expression vector for the recombinant genes. The $M$. tuberculosis antigens of Ag85B (accession no. Q847N4), Rv0475 (accession no. CCP43209) and Rv2031 (accession no. AJF03385.1) were synthesized based on their epitope-encoding sequences of Ag85B $101-115,126-140,261-$ 275, Rv0475 $5_{34-59}$ and Rv2031 $14-70,95-108$ proteins and assembled into one fusion gene designated as AR before being cloned into pJET1.2/blunt cloning vector (Integrated DNA Technologies, Singapore). The epitope-encoding sequences were selected based on their bioinformatics analysis that showed strong potential for inducing effective and protective immune response against TB. The relevant features of bacterial strains and plasmids used in this study are described in Table 2.

\section{DNA techniques and transformation}

The methods for molecular cloning were performed according to Sambrook et al. [32]. Genomic DNA of $L$. lactis was isolated according to Leenhouts et al. [33]. Plasmid DNA was obtained using Promega Mini-Prep Plasmid Extraction kit (Promega, USA) as specified by the supplier. Restriction enzymes, T4 DNA ligase, and deoxynucleotides were obtained from Roche Diagnostics (Germany) and were used according to the supplier's instructions. Polymerase chain reactions (PCR) were carried out via T100 Thermal Cycler (BioRad, USA) using Pfu DNA polymerase according to the instructions of the manufacturer (Fisher Scientific, USA). PCR products were purified using the Wizard ${ }^{\circ} \mathrm{SV}$ Gel and PCR Clean-Up System (Promega, USA) and was performed according to manufacturer's protocol. E. coli Rosetta strain was transformed with the recombinant vector by the heat-shock method.

\section{Construction and expression of plasmid pRSF:ARL}

In order to construct the pRSF:ARL expression plasmid, $\mathrm{AR}$ and lys $\mathrm{M}$ DNA sequences were individually amplified using pre-designed primers (Table 3) from pJET:AR and from genomic DNA of L. lactis MG1363, respectively. The PCR reactions were carried based on these parameters; denaturation step at $95^{\circ} \mathrm{C}$ for $5 \mathrm{~min}$ and amplification in 25 cycles of $1 \mathrm{~min}$ at $95^{\circ} \mathrm{C}, 30 \mathrm{~s}$ at optimum annealing temperature, which was determined by gradient temperature ranging from 45 to $60^{\circ} \mathrm{C}$, and 1 min at $72^{\circ} \mathrm{C}$ followed by one cycle at $72{ }^{\circ} \mathrm{C}$ for $10 \mathrm{~min}$. Gel purified PCR products of AR and lysM were

Table 2 Bacterial strains and plasmids used in this study

\begin{tabular}{|c|c|c|}
\hline Strain or plasmid & Relevant Characteristics & Source or reference \\
\hline \multicolumn{3}{|l|}{ Strains } \\
\hline Lactococcus lactis MG1363 & L. lactis subsp. cremoris; Lac $^{-}$, plasmid-free derivative of NCDO712 & [23] \\
\hline Lactobacillus plantarum Pa21 & Malaysia local plant, Pandanus amaryllifoliusisolate, plasmid-free strain & [31] \\
\hline E. coli Rosetta (DE3)pLysS & Camr', Expression host for all E. coli vectors, E. coli BL21 derivative & Novagen \\
\hline \multicolumn{3}{|l|}{ Plasmids } \\
\hline pRSFDuet-1 & $3.8 \mathrm{~kb}, \mathrm{Kan}^{\mathrm{r}}$, E. coli expression vector & Invitrogen \\
\hline pJET1.2/blunt & $2.9 \mathrm{~kb}, \mathrm{Amp}^{\mathrm{r}}$, E. coli cloning vector, & Thermo Scientific \\
\hline pJET:AR & $3.5 \mathrm{~kb}, \mathrm{Amp}^{\mathrm{r}}, \mathrm{pJET} 1.2$ derivative carrying AR gene & IDT \\
\hline pRSF:ARL & $4.98 \mathrm{~kb}, \mathrm{Kan}^{\mathrm{r}}$, pRSFDuet-1 derivative carrying ARL fusion gene & This study \\
\hline pRSF:AR & 4.4 kb, Kan', pRSFDuet-1 derivative carrying AR fusion gene & This study \\
\hline
\end{tabular}


Table 3 Primers used in this study

\begin{tabular}{|c|c|c|}
\hline Fragment & Primer sequence $\left(5^{\prime} \text { to } 3^{\prime}\right)^{a}$ & Expected product size (base pair) \\
\hline \multirow[t]{2}{*}{ ARL } & Forward GGATCCGAATTCGCTGACCAGCGAGCTGCCGC & 1244 \\
\hline & Reverse GCGGCCGCTTATTTATTCGTAGATACTGAC & \\
\hline \multirow[t]{2}{*}{ lysM } & Forward CTGCAGCCATGGCGGCTGGAAGACGAGATGAAA & 608 \\
\hline & Reverse GCGGCCGCTTATTTAATCGTAGATACTGAC & \\
\hline \multirow[t]{3}{*}{$A R$} & Forward GGATCCGAATTCGCTGACCAGCGAGCTGCCGC & 613 \\
\hline & 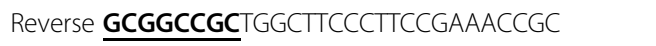 & \\
\hline & 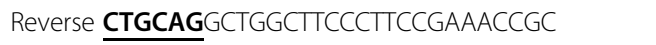 & \\
\hline \multirow[t]{2}{*}{ pRSF:Duet-1 } & Forward GGATCTCGACGCTCTCCCT & 200 \\
\hline & Reverse TTGTACACGGCCGCATAATC & \\
\hline
\end{tabular}

${ }^{a}$ Restriction enzyme (RE) sites are shown as bold and underlined is either BamHI (GGATCC), Pstl (CTGCAG) or Notl (GCGGCCGC)

digested with Pst $\mathrm{I}$, purified and ligated together at a $1: 1$ ratio using T4 ligase (Roche, Germany) to produce ligated product of the ARL gene. Subsequently, the ARL fusion gene was PCR amplified and cloned into pRSFDuet-1 plasmid. Both insert and plasmid were double digested with $\mathrm{BamHI} / \mathrm{Not} \mathrm{I}$ before ligation at $14^{\circ}$ $\mathrm{C}$ overnight at 1:4 plasmid/insert ratio. The newly constructed plasmid pRSF:ARL was then introduced into $E$. coli Rosetta (DE3) pLySs. After transformation, verification of the recombinant plasmid was performed by restriction enzyme analysis and PCR, and the inserted ARL gene was validated for its sequences via sequencing analysis approach (First Base, Malaysia). Plasmid pRSF:AR without the lys $M$ sequence was constructed similarly to pRSF:ARL. The resulting plasmids pRSF:ARL and pRSF:AR are illustrated in Fig. 1.

Two hundred-mL cultures of Terrific Broth (TB) (EMD BioSciences, San Diego, CA) medium with kanamycin $(100 \mu \mathrm{g} / \mathrm{mL})$ were used to over-express the E. coli transformants containing pRSF:ARL and pRSF:AR, respectively. The cultures were grown at $37^{\circ} \mathrm{C}$ until $\mathrm{OD}_{600}$ $0.5-0.7$ before they were induced by adding IPTG (1 $\mathrm{mM}$ final concentration) for $6 \mathrm{~h}$ at $25^{\circ} \mathrm{C}$ with $150 \mathrm{rpm}$ shaking. The cells were then harvested by centrifugation for $10 \mathrm{~min}$ at $5000 \mathrm{~g}$ at $4{ }^{\circ} \mathrm{C}$. The cell pellets $(\sim 0.1 \mathrm{~g})$ were re-suspended in $10 \mathrm{~mL}$ PBS ( $\mathrm{pH} 7.4$ ) with sonication for $7 \mathrm{~min}$ ( $1 \mathrm{~s} \mathrm{on} / 2 \mathrm{~s}$ off $)$ at $40 \%$ pulse mode power via the Omni Ruptor 4000 (Omni International, USA). The soluble and insoluble fractions were separated by centrifugation at $4{ }^{\circ} \mathrm{C}$ for $20 \mathrm{~min}$ at $5000 \mathrm{~g}$, and analyzed in $12 \%$ SDS-PAGE. Target protein was estimated by densitometric analysis using ImageJ software [34].

\section{Solubilization and purification of ARL}

The solubilization and purification of ARL was performed according to Mustafa et al. [35]. NLS concentrations of $0.5,1,3 \%$ or $5 \%(\mathrm{w} / \mathrm{v})$ in $10 \mathrm{~mL}$ solubilizing buffer (40 mMTris- $\mathrm{HCl}, \mathrm{pH} 8$ ) were used to treat the re-suspended insoluble fraction (containing IBs) under constant agitation at $180 \mathrm{rpm}$ for $24 \mathrm{~h}$ at $20^{\circ} \mathrm{C}$. Centrifugation of the suspension was carried out at $4400 \mathrm{~g}$ for $20 \mathrm{~min}$ at $4{ }^{\circ} \mathrm{C}$ and the supernatant was filter sterilized with $0.45 \mu \mathrm{m}$ membrane filter. In order to achieve a final NLS concentration of $0.1 \%(\mathrm{w} / \mathrm{v})$, binding buffer $(20 \mathrm{mM}$ imidazole, $40 \mathrm{mM}$ Tris- $\mathrm{HCl}$ ) was added to the supernatant accordingly with its $\mathrm{pH}$ adjusted to $\mathrm{pH}$ 7.4. Subsequently, the supernatant was loaded onto a $\mathrm{Ni}^{2+}-\mathrm{NTA}$ column (GE Healthcare, USA) followed by a washing step, three times with binding buffer $(20 \mathrm{mM}$ imidazole, $40 \mathrm{mM}$ Tris- $\mathrm{HCl}$ ) before being eluted with elution buffer (500 mM imidazole, $40 \mathrm{mM}$ Tris- $\mathrm{HCl}$ ). Analysis of the eluted protein and its concentration was determined based on SDS-PAGE analysis and Bradford assay, respectively.

\section{Binding of ARL onto $L$. plantarum cell wall surface}

A $5 \mathrm{~mL}$ MRS broth (Difco, Detroit, MI) was inoculated with a single colony of L. plantarum at $37^{\circ} \mathrm{C}$ in an overnight incubation. The $0.1 \mathrm{~mL}$ overnight culture was added into a new $5 \mathrm{~mL}$ MRS for inoculation at $37^{\circ} \mathrm{C}$. The cells culture was grown until it reached optical density of $\mathrm{OD}_{600} 0.5-0.7$. The cells were then pelleted at $4000 \mathrm{~g}$ for $5 \mathrm{~min}$ and the cell pellet was re-suspended in $1 \mathrm{~mL}$ of MRS broth. The $1 \mathrm{~mL}$ of bacterial suspension was then mixed with $250 \mu \mathrm{g}$ of purified ARL and incubated at $37^{\circ} \mathrm{C}$ for $2 \mathrm{~h}$. The cells were pelleted at $2000 \mathrm{~g}$ for $5 \mathrm{~min}$ and then washed with PBS for 3 times. Finally, the pellet was re-suspended in $1 \mathrm{~mL}$ of PBS and stored at $4{ }^{\circ} \mathrm{C}$ until further usage. The sample was further analyzed via immunofluorescent staining and whole cell ELISA assays as described below. Lactobacilli cells mixed with $200 \mu \mathrm{L}$ of PBS were used as negative control.

\section{Immunofluorescence microscopy and ELISA}

The qualitative confirmation of ARL binding to the $L$. plantarum cell wall was conducted at Day 0 via immunofluorescence visualization method using mouse anti-his IgG monoclonal antibody (Novagen, USA) as 
the primary antibody and goat anti-mouse IgG conjugated Fluorescein Conjugated Antibody (FITC)- (Calbiochem, USA) as the secondary antibody. Following the attachment procedure, the Lactobacilli cells were harvested and re-suspended in $300 \mu \mathrm{L}$ of PBS. About 20$30 \mu \mathrm{l}$ of $1 \times 10^{8} \mathrm{cfu} / \mathrm{mL}$ cells was dropped on slides coated with poly-L-lysine; air dried and then washed with PBS. The attached cells were fixed with $4 \%(\mathrm{w} / \mathrm{v})$ paraformaldehyde for $20 \mathrm{~min}$ at $\mathrm{RT}$, followed with a washing step $(3 \mathrm{x})$, each for $5 \mathrm{~min}$. In the next step, the cells were incubated with $3 \%(\mathrm{w} / \mathrm{v})$ BSA in PBS for 30 min at RT, to block non-specific binding sites. After washing with PBS, the cells were incubated with primary antibody of anti-his monoclonal antibody $(0.2 \mu \mathrm{g} / \mu \mathrm{L})$ (Novagen, USA) diluted at ratio 1:200 in PBS with 1\% BSA followed by incubation at RT for $1 \mathrm{~h}$. The cells were washed and then incubated with secondary antibody goat anti-mouse IgG-FITC $(1 \mu \mathrm{g} / \mu \mathrm{L})$ (Calbiochem, USA) diluted at 1:200 in PBS with 1\% BSA, at RT for $1 \mathrm{~h}$. After the washing step, the slide was dried and analyzed by a fluorescence microscope (Nikon E200, Japan).

Whole cell ELISA was used to semi-quantitatively verify the binding stability and frequency of ARL protein attached onto the cell wall of $L$. plantarum for 5 days. At Day 0, $200 \mu \mathrm{L}$ from the stored sample of Lactobacilli cells formerly incubated with the ARL proteins were harvested at $2000 \mathrm{~g}$ for $5 \mathrm{~min}$. After that the cells were fixed in a 1 $\mathrm{mL}$ Eppendorf tube (Sigma, USA) with $4 \%(\mathrm{w} / \mathrm{v})$ paraformaldehyde for $20 \mathrm{~min}$ at RT, followed by 3 times washing with PBS at $2000 \mathrm{~g}$ for $5 \mathrm{~min}$. The cells were then incubated with blocking solution [3\% (w/v) BSA in PBS] for 30 min at RT. After washing, the cells were incubated with mouse anti-his monoclonal antibody $(0.2 \mu \mathrm{g} / \mu \mathrm{L})$ (Novagen, USA) as primary antibody at a ratio of 1:200 in PBS with $1 \%$ BSA, followed by $1 \mathrm{~h}$ incubation at RT. The cells were then pelleted washed and incubated with horseradish peroxidase (HRP)-conjugated goat anti-mouse IgG antibody $(1 \mu \mathrm{g} / \mu \mathrm{L})$ (Novagen, USA) as secondary antibody at a ratio of 1:200 in PBS with 1\% BSA for $1 \mathrm{~h}$ at RT. After washing, the cells were pelleted and finally re-suspended in $200 \mu \mathrm{L}$ of PBS. Cells were then normalized to $\mathrm{OD}_{600}$ of 3 where after an appropriate volume of the bacterial suspension was added onto the 96 well ELISA plate (Sigma, USA). Subsequently $50 \mu \mathrm{L}$ of substrate (BM Blue, Roche, Germany) was mixed in the wells of the ELISA plate and then incubated at RT for $20 \mathrm{~min}$ followed with the addition of $50 \mu \mathrm{L}$ of stop solution $\left(1 \mathrm{M} \mathrm{H}_{2} \mathrm{SO}_{4}\right)$. The absorbance was measured at $490 \mathrm{~nm}$ using an ELISA reader (Tecan Infinite F50, Switzerland). On 5 subsequent days, an aliquot of the cells was taken and cells were subjected to the same treatment after fixation with $4 \%(\mathrm{w} / \mathrm{v})$ paraformaldehyde as mentioned earlier. For both IF and whole cell ELISA, Lactobacilli cells incubated with PBS was used as negative control.

\section{Statistical analysis}

All tests were performed using the student T-test function of the StatView program, version 5.0 (SAS Institute Inc.; Cary, NC). All results were valued as means \pm standard error.

\section{Additional files}

Additional file 1: Figure S1. Confirmation of $A R L$ and $A R$ insert in pRSF:Duet plasmid by double restriction enzyme digests. (DOCX 692 kb)

Additional file 2: Figure S2. Sequencing results for $A R L$ and $A R$ in pRSF:Duet plasmid. (DOCX $48 \mathrm{~kb}$ )

Additional file 3: Figure S3. Western blot analysis of ARL from the total protein fraction sample. (DOCX $60 \mathrm{~kb}$ )

\section{Abbreviations}

AR: Ag85B-Rv0475-Rv203; ARL: Ag85B-Rv0475-Rv203-LysM; BCG: Bacillus Calmette-Guérin; BSA: Bovine serum albumin; ELISA: Enzyme-linked immunosorbent assay; FITC: Fluorescein isothiocyanate; GMO: Genetically modified organism; HRP: Horseradish peroxidase; SDS-PAGE, sodium dodecyl sulfate polyacrylamide gel electrophoresis; IBs: Inclusion bodies;

IgG: Immunoglobulin G; LAB: Lactic acid bacteria; LysM: Lysin motif; NLS: Nlaurylsarcosine; PBS: Phosphate buffered saline; RT: Room temperature; Th1: T-helper 1

\section{Acknowledgements}

The authors wish to thank Ridzuan for his assistance in the immunofluorescence microscopy work.

\section{Funding}

This work was supported by a research grant from the Ministry of Higher Education of Malaysia (MOHE) under the grant number 700-2/1/LRGS/ 5525500. The funder had no role in the study design, data collection and analysis, or writing of the manuscript.

\section{Availability of data and materials}

The authors declare that [the/all other] data supporting the findings of this study are available within the article [and its supplementary information files].

\section{Authors' contributions}

AM helped to design the experiments, performed experimental work, analyzed data and drafted the manuscript. SS and JK performed experimental work and analyzed data. AS, MA, RR and KY helped to design the experiments and to analyze and interpret data. All authors read and approved the final manuscript.

Ethics approval and consent to participate Not applicable.

\section{Consent for publication}

Not applicable.

\section{Competing interests}

The authors declare that they have no competing interests.

\section{Publisher's Note}

Springer Nature remains neutral with regard to jurisdictional claims in published maps and institutional affiliations.

\section{Author details}

${ }^{1}$ Department of Cell and Molecular Biology, Faculty of Biotechnology and Biomolecular Sciences, Universiti Putra Malaysia, 43400 Serdang, Selangor, Malaysia. ${ }^{2}$ Department of Microbiology, Faculty of Biotechnology and Biomolecular Sciences, Universiti Putra Malaysia, 43400 Serdang, Selangor, Malaysia. ${ }^{3}$ Department of Pathology, Faculty of Medicine and Health Sciences, Universiti Putra Malaysia, 43400 Serdang, Selangor, Malaysia. 
${ }^{4}$ Institute of Bioscience, Universiti Putra Malaysia, 43400 Serdang, Selangor, Malaysia. ${ }^{5}$ Malaysia Genome Institute, 43000 Kajang, Selangor, Malaysia.

\section{Received: 25 May 2018 Accepted: 30 April 2019}

Published online: 14 May 2019

\section{References}

1. Hanekom WA, Dockrell HM, Ottenhoff THM, Doherty TM, Fletcher H, Mcshane H, Weichold HDF, Parida SK, Fruth UJ. Immunological outcomes of new tuberculosis vaccine trials : WHO panel recommendations. PLoS Med. 2008;5:1033-6.

2. World Health Organization. Global Tuberculosis Report. Who/CDS/TB/2018 25. Geneva: WHO; 2018. p. 2018.

3. Grange JM, Brunet LR, Rieder HL. Immune protection against tuberculosis: when is immunotherapy preferable to vaccination? Tuberculosis. 2011:91: 179-85.

4. Ghadimi D, de Vrese M, Heller KJ, Schrezenmeir J. Lactic acid bacteria enhance autophagic ability of mononuclear phagocytes by increasing Th1 autophagy-promoting cytokine (IFN-gamma) and nitric oxide (NO) levels and reducing Th2 autophagy-restraining cytokines (IL-4 and IL-13) in response to Mycobacterium. Int Immunopharmacol. 2010;10:694-706.

5. Mercenier A, Müller-Alouf H, Grangette C. Lactic acid bacteria as live vaccines. Curr Issues Mol Biol. 2000;2:17-25.

6. Medina E, Guzmán CA. Use of live bacterial vaccine vectors for antigen delivery: potential and limitations. Vaccine. 2001;19:1573-80.

7. Moeini H, Rahim RA, Omar AR, Shafee N, Yusoff K. Lactobacillus acidophilus as a live vehicle for oral immunization against chicken anemia virus. Appl Microbiol Biotechnol. 2011;90:77-88.

8. Åvall-jääskeläinen S, Kylä-nikkilä K, Kahala M, Åvall-ja S, Kyla K. Surface display of foreign epitopes on the surface display of foreign epitopes on the Lactobacillus brevis S-layer. Appl Environ Microbiol. 2002;68:593.

9. Liu D, Wang X, Ge J, Liu S, Li Y. Comparison of the immune responses induced by oral immunization of mice with Lactobacillus casei-expressing porcine parvovirus VP2 and VP2 fused to Escherichia coli heat-labile enterotoxin B subunit protein. Comp Immunol Microbiol Infect Dis. 2011;34: 73-81.

10. Steidler L, Viaene J, Fiers W, Remaut E. Functional display of a heterologous protein on the surface of Lactococcus lactis by means of the cell wall anchor of Staphylococcus aureus protein a. Appl Environ Microbiol. 1998;64: 342-5.

11. Visweswaran GRR, Leenhouts K. Exploiting the peptidoglycan-binding motif , LysM , for medical and industrial applications. Appl Microbiol Biotechnol. 2014:4331-45

12. Ramasamy R, Yasawardena S, Zomer A, Venema G, Kok J, Leenhouts K. Immunogenicity of a malaria parasite antigen displayed by Lactococcus lactis in oral immunisations. Vaccine. 2006;24:3900-8.

13. Steen A, Buist G, Leenhouts KJ, El Khattabi M, Grijpstra F, Zomer AL, Venema G, Kuipers OP, Kok J. Cell wall attachment of a widely distributed peptidoglycan binding domain is hindered by cell wall constituents. J Biol Chem. 2003:278:23874-81.

14. Xin Q, Niu H, Li Z, Zhang G, Hu L, Wang B, Li J, Yu H, Liu W, Wang Y, Li R, Xian Q, Wang Y, Zhang Y, Jing T, Ma X, Zhu B. Subunit vaccine consisting of multi-stage antigens has high protective efficacy against Mycobacterium tuberculosis infection in mice. PLoS One. 2013;8:e72745.

15. Shi S, Yu L, Sun D, Liu J, Hickey AJ. Rational design of multiple TB antigens TB10.4 and TB10.4-Ag85B as subunit vaccine candidates against Mycobacterium tuberculosis. Pharm Res. 2010;27:224-35.

16. Smith I. Mycobacterium tuberculosis pathogenesis and molecular determinants of virulence. Clin Microbiol Rev. 2003:16:463-96.

17. Sable SB, Verma I, Khuller GK. Multicomponent antituberculous subunit vaccine based on immunodominant antigens of Mycobacterium tuberculosis. Vaccine. 2005:23:4175-84.

18. Piubelli L, Campa M, Temporini C, Binda E, Mangione F, Amicosante M, Terreni M, Marinelli F, Pollegioni L. Optimizing Escherichia coli as a protein expression platform to produce Mycobacterium tuberculosis immunogenic proteins. Microb Cell Factories. 2013;12:115.

19. Singh SM, Panda AK. Solubilization and refolding of bacterial inclusion body proteins. J Biosci Bioeng. 2005:99:303-10.

20. Francis VG, Majeed MA, Gummadi SN. Recovery of functionally active recombinant human phospholipid scramblase 1 from inclusion bodies using N-lauroyl sarcosine. J Ind Microbiol Biotechnol. 2012;39:1041-8.
21. Peternel S, Grdadolnik J, Gaberc-Porekar V, Komel R. Engineering inclusion bodies for non denaturing extraction of functional proteins. Microb Cell Factories. 2008;7:34.

22. Tao H, Liu W, Simmons BN, Harris HK, Cox TC, Massiah MA. Purifying natively folded proteins from inclusion bodies using sarkosyl, triton X-100, and CHAPS. Biotechniques. 2010;48:61-4.

23. Rodriguez JM, Cintas LM, Casaus P, Horn N, Dodd HM, Hernandez PE, Gasson MJ. Isolation of nisin-producing Lactococcus lactis strains from dry fermented sausages. J Appl Bacteriol. 1995;78:109-15.

24. Villaverde A, Carrio MM. Protein aggregation in recombinant bacteria: biological role of inclusion bodies. Biotechnol Lett. 2003:25:1385-95.

25. Burgess RR. Refolding solubilized inclusion body proteins. Methods Enzymol 2009;9:259-82

26. Raha AR, Varma NRS, Yusoff K, Ross E, Foo HL. Cell surface display system for Lactococcus lactis: a novel development for oral vaccine. Appl Microbiol Biotechnol. 2005;68:75-81.

27. Visweswaran GRR, Steen A, Leenhouts K, Szeliga M, Ruban B, HesselingMeinders A, Dijkstra BW, Kuipers OP, Kok J, Buist G. AcmD, a homolog of the major autolysin AcmA of Lactococcus lactis, binds to the cell wall and contributes to cell separation and autolysis. PLoS One. 2013;8:1-11.

28. Steen A, Buist G, Horsburgh GJ, Venema G, Kuipers OP, Foster SJ, Kok J. AcmA of Lactococcus lactis is an N-acetylglucosaminidase with an optimal number of LysM domains for proper functioning. FEBS J. 2005;272:2854-68.

29. Wang W, Nema S, Teagarden D. Protein aggregation-pathways and influencing factors. Int J Pharm. 2010;390:89-99.

30. Poquet I, Saint V, Seznec E, Simoes N, Bolotin A, Gruss A. HtrA is the unique surface housekeeping protease in Lactococcus lactis and is required for natural protein processing. Mol Microbiol. 2000;35:1042-51.

31. Maidin MST, Song AA-L, Jalilsood T, Sieo CC, Yusoff K, Rahim RA. Construction of a novel inducible expression vector for Lactococcus lactis M4 and Lactobacillus plantarum Pa21. Plasmid. 2014;74:32-8.

32. Sambrook J, Russel DW. Molecular cloning: a laboratory manual, 3rd edn. Cold Spring Harbor Laboratory Press; 2001.

33. Leenhouts K, Buist G, Bolhuis A, ten Berge A, Kiel J, Mierau I, Dabrowska M, Venema G, Kok J. A general system for generating unlabelled gene replacements in bacterial chromosomes. Mol Gen Genet. 1996;253:217-24.

34. Zou Y, Mi J, Wang W, Lu J, Zhao W, Liu Z, Hu H, Yang Y, Gao X, Jiang B, Shao C, Gong Y. CUL4B promotes replication licensing by up-regulating the CDK2-CDC6 cascade. J Cell Biol. 2013;200:743-56.

35. Mustafa AD, Kalyanasundram J, Sabidi S, Adelene AA, Abdullah M, Raha AR, Yusoff K. Proof of concept in utilizing in-trans surface display system of Lactobacillus plantarum as mucosal tuberculosis vaccine via oral administration in mice. BMC Biotechnol. 2018;18:63.

Ready to submit your research? Choose BMC and benefit from:

- fast, convenient online submission

- thorough peer review by experienced researchers in your field

- rapid publication on acceptance

- support for research data, including large and complex data types

- gold Open Access which fosters wider collaboration and increased citations

- maximum visibility for your research: over $100 \mathrm{M}$ website views per year

At BMC, research is always in progress.

Learn more biomedcentral.com/submission 